\title{
Avances en el tratamiento del cáncer escamoso de cabeza y cuello
}

García Sáenz JA, Bueno Muiño C. Avances en el tratamiento del cáncer escamoso de cabeza y cuello. An Med Interna (Madrid) 2008; 25: 157-158.

El Cáncer Escamoso de Cabeza y Cuello (CECyC) engloba un grupo, más o menos homogéneo, de tumores que representan un reto oncológico, tanto por su incidencia y mortalidad, como por la morbilidad funcional y estética que ocasionan. En los últimos años ha habido notables avances en el manejo inicial de estos enfermos, gracias a la cooperación multidisciplinaria en los tratamientos. Cuando se diagnostica de forma precoz (estadio I o II), el CECyC puede curarse con cirugía y/o radioterapia. Desafortunadamente hasta el $75 \%$ de los pacientes con CECyC se diagnostican con enfermedad localmente avanzada. En estos estadios más avanzados, se han integrado estrategias más recientes al tratamiento local, tales como la quimioterapia de inducción y/o quimiorradioterapia; sin embargo, la tasa de supervivencia a 5 años continúa siendo de alrededor del $30 \%$, y el $60 \%$ de los pacientes experimentarán una recaída locorregional o a distancia en los 2 años siguientes al tratamiento inicial.

Además hay situaciones muy desfavorables, como son los pacientes con $\mathrm{CECyC}$ recidivado o metastásico. El tratamiento estándar de CECyC recidivado o metastásico es la quimioterapia con platino, generalmente con dobletes, que obtienen respecto a la monoterapia una mayor tasa de respuesta, alrededor de $30 \%$, pero no de supervivencia 6 a 8 meses. Tras el fracaso de este tratamiento nos encontraríamos en una situación todavía más desalentadora. En consecuencia, se esperan con urgencia nuevos tratamientos que sean más eficaces y que puedan proporcionar un mejor perfil de seguridad en CECyC. Esta es la razón del desarrollo de nuevos fármacos o combinaciones de fármacosen la enfermedad avanzada refractaria. Los mayores esfuerzos en este contexto están encaminados a la búsqueda de fármacos dirigidos al receptor del factor de crecimiento epidérmico (EGF-R).

EGF-R es una proteína de membrana celular que posee un dominio extracelular, para unirse al ligando, una región transmembrana y un dominio intracelular que integra el dominio tirosín-quinasa y varias zonas de fosforilación. Cuando el ligando se une al EGF-R, se activa el dominio intracelular del EGFR y se disparan señales tirosín-quinasa intracelulares muy potentes que inducen el crecimiento de células tumorales, invasión, angiogénesis y metástasis. Se ha visto que la mayoría de los CECyC presenta sobrexpresión de EGF-R y ésta se correlaciona con un pronóstico más desfavorable.

Con el fin de inhibir la proliferación de células que expresan EGFR, se han sintetizado antagonistas del EGFR que bloquean en el receptor el lugar de unión al ligando. Las dos estrategias de diana molecular más desarrolladas en estos tumores son los inhibidores de tirosín-quinosa, que actúan en la porción intracelular del receptor y los anticuerpos monoclonales dirigidos directamente a la porción extracelular del receptor, como por ejemplo cetuximab. Cetuximab es un anticuerpo monoclonal quimérico que se une al dominio extracelular del EGF-R y ha sido recientemente aprobado para el tratamiento combinado con radioterapia radical en $\mathrm{CECyC}$ irresecables y en radioterapia adyuvante en tumores resecables; actualmente se intentan mejorar los resultados en combinación también con quimioterapia, dado a la ausencia de superposición de toxicidades con la esta última.

En el artículo de este número, Escobar y colaboradores, describen su experiencia con cetuximab como segunda línea de Carcinoma Escamoso de Cabeza y Cuello recurrente o metastásico tras un fracaso a una primera línea de quimioterapia de platino. Evidentemente, al tratarse de un estudio retrospectivo, en un solo centro y con un tamaño muestral muy pequeño, las conclusiones que deriven del mismo deben interpretase con cautela. Sin embargo hay algunas conclusiones que podemos resaltar.

Por una parte, los pacientes en esta situación de enfermedad refractaria a cisplatino tienen un deterioro importante en su calidad de vida. Por esta razón la búsqueda de agentes terapéuticos con un perfil de toxicidad aceptable y previsible, como cetuximab $\mathrm{u}$ otros tratamientos específicos dirigidos al receptor de factor de crecimiento epidérmico, es un campo que debe ser explorado. La toxicidad de la serie descrita por la Dra. Escobar, así como otras series similares, es baja y previsible.

No obstante, aunque el número de pacientes que se benefician de una estabilización de la enfermedad por un periodo de al menos 16 semanas es algo mayor, la tasa de respuesta objetiva a cetuximab como segunda línea de tratamiento antitumoral para el manejo de estos pacientes es decepcionante. 
Es cierto que, de forma global, tras el fracaso de una primera línea basada en platinos, los pacientes con carcinoma escamoso de cabeza y cuello tienen un pronóstico sombrío; sin embargo no parece que el tratamiento con cetuximab en monoterapia ofrezca resultados alentadores en este contexto.

Para poder mejorar la supervivencia y la calidad de vida de esta población deberemos realizar avances en otras direcciones. Una posibilidad es identificar antes del inicio de los tratamientos, qué pacientes son los que van a responder a una determinada terapia; por ejemplo reconocer un marcador biológico que prediga la respuesta a un determinado tratamiento de diana molecular.

Otra posibilidad es la combinación de tratamientos citotóxicos con terapias de diana molecular en escenarios más iniciales de la enfermedad, como por ejemplo, terapias complementarias a la cirugía, tratamientos de inducción antes del tratamiento local, tratamientos concomitantes con radiotera-

\section{Bibliografía}

1. Bonner JA, Harari PM, Giralt J, et al. Radiotherapy pluscetuximab for squamous-cell carcinoma of the head andneck. N Engl J Med 2006; 354:567-578.

2. Cohen EE. Role of epidermal growth factor receptor pathway-targeted therapy in patients with recurrent and/or metastatic squamous cell carcinoma of the head and neck. J Clin Oncol 2006; 24: 265965.

3. CW, Morgan MA, Eckardt A. Targeting EGF-receptor-signalling in squamous cell carcinomas of the head and neck. Br J Cancer 2007; 96: 408-16.

4. Escobar Álvarez Y, Khosravi Shahi P, Encinas García S, Izarzugaza Perón Y. Efectividad de Cetuximab en monoterapia en el tratamiento de cánceres de cabeza y cuello avanzado refractario. An Med Interna (Madrid) 2008; 25: 159-162.

5. Le Tourneau C, Faivre S, Siu LL. Molecular targeted therapy of head and neck cancer: review and clinical development challenges. Eur J pia local definitiva o bien en la primera línea de la enfermedad recidivada o metastásica. Los progresos que estamos experimentando en estas situaciones sí son notables, y están consiguiendo que estos enfermos vivan más y mejor.

Por último, el mayor conocimiento de los mecanismos de proliferación, invasión y metástasis de los tumores están abriendo las puertas a la investigación de nuevos fármacos que, progresivamente, se irán incorporando en el complejo tratamiento multidisciplinar del cáncer de cabeza y cuello.

\section{J. A. GARCÍA SÁENZ, C. BUENO MUIÑO ${ }^{1}$}

Servicio de Oncología Médica. Hospital Clínico San Carlos. Madrid. ${ }^{1}$ Hospital Infanta Cristina. Parla. Madrid
Cancer 2007; 43: 2457-66.

6. Mendenhall WM, Riggs CE Jr, Cassisi NJ. Treatment of head and neck cancers. En: DeVita VT Jr, Hellman S, Rosenberg SA, eds.. Cancer: Principles and Practice of Oncology. $7^{\mathrm{a}}$ ed. Philadelphia, Pa: Lippincott Williams \& Wilkins; 2005. p. 662-732.

7. Posner MR, Hershock DM, Blajman CR, et al. Cisplatin and fluorouracil alone or with docetaxel in head and neck cancer. N Engl J Med 2007; 357: 1705-15.

8. Vermorken JB, Remenar E, van Herpen C, et al. Cisplatin, fluorouracil, and docetaxel in unresectable head and neck cancer. N Engl J Med 2007; 357: 1695-704.

9. Vermorken JB, Trigo J, Hitt R, et al. Open-label, uncontrolled, multicenter phase II study to evaluate the efficacy and toxicity of cetuximab as a single agent in patients with recurrent and/or metastatic squamous cell carcinoma of the head and neck who failed to respond to platinumbased therapy. J Clin Oncol 2007; 25: 2171-7. 